\title{
Modeling Combined Immunosuppressive and Anti-inflammatory Effects of Dexamethasone and Naproxen in Rats Predicts the Steroid-Sparing Potential of Naproxen ${ }^{\text {ฐ }}$
}

\author{
Xiaonan Li, Debra C. DuBois, Dawei Song, Richard R. Almon, William J. Jusko, and Xijing Chen \\ Clinical Pharmacokinetics Laboratory, School of Basic Medicine and Clinical Pharmacy, China Pharmaceutical University, Nanjing, \\ Jiangsu, People's Republic of China (X.L., X.C.); Department of Pharmaceutical Sciences, School of Pharmacy and Pharmaceutical \\ Sciences (X.L., D.C.D., D.S., R.R.A., W.J.J.), and Department of Biological Sciences (D.C.D., R.R.A.), State University of New York at \\ Buffalo, Buffalo, New York
}

Received February 20, 2017; accepted April 13, 2017

\begin{abstract}
Dexamethasone (DEX), a widely prescribed corticosteroid, has long been the cornerstone of the treatment of inflammation and immunologic dysfunctions in rheumatoid arthritis. Corticosteroids are frequently used in combination with other antirheumatic agents such as nonsteroidal anti-inflammatory drugs (NSAIDs) and disease-modifying antirheumatic drugs to mitigate disease symptoms and minimize unwanted effects. We explored the steroid dose-sparing potential of the NSAID naproxen (NPX) with in vitro and in vivo studies. The single and joint suppressive effects of DEX and NPX on the in vitro mitogen-induced proliferation of $T$ lymphocytes in blood and their anti-inflammatory actions on paw edema were investigated in female and male Lewis rats with collagen-induced arthritis (CIA). As expected, DEX was far more
\end{abstract}

potent than NPX in these systems. Mathematical models incorporating an interaction term $\psi$ were applied to quantitatively assess the nature and intensity of pharmacodynamic interactions between DEX and NPX. Modest synergistic effects of the two drugs were found in suppressing the mitogenic response of $T$ lymphocytes. A pharmacokinetic/pharmacodynamic/disease progression model integrating dual drug inhibition quantitatively described the pharmacokinetics, time-course of single and joint anti-inflammatory effects (paw edema), and sex differences in CIA rats, and indicated additive effects of DEX and NPX. Further model simulations demonstrated the promising steroid-sparing potential of NPX in CIA rats, with the beneficial effects of the combination therapy more likely in males than females.

\section{Introduction}

Rheumatoid arthritis (RA) is one of the most prevalent chronic inflammatory autoimmune diseases, causing pain, swelling and stiffness of joints, as well as cartilage destruction and bone erosion. It preferentially affects synovial tissues but is also deleterious to other organ systems, producing various systemic comorbidities. With the combination of a susceptible genetic background and environmental insults, a sequence of complex immune activation cascades are involved in the disease initiation and progression of RA (Smolen et al., 2016). In particular, active immune cells present in the synovial tissues, especially T-lymphocytes, play a key role in promoting continuous autoimmune reactions by releasing various proinflammatory mediators such as cytokines and prostaglandins (PG) (Cavender et al., 1987; McInnes and Schett, 2011). Also, noticeable sex differences in the prevalence, disease course, and prognosis occur in RA,

This work was supported the China Scholarship Council (to X.L.) and the National Institutes of Health National Institute of General Medical Sciences [Grant R01-GM24211].

https://doi.org/10.1124/dmd.117.075614.

S This article has supplemental material available at dmd.aspetjournals.org. with females more affected (Jawaheer et al., 2006; van Vollenhoven, 2009). Conventional medications such as nonsteroidal anti-inflammatory drugs (NSAIDs) and corticosteroids (CS) remain first-line therapies for RA because of their rapid symptomatic effects compared with sloweracting disease-modifying antirheumatic drugs and biologic agents (Gaffo et al., 2006).

CS have long been used for treatment of RA owing to their potent anti-inflammatory and immunosuppressive properties. They not only provide rapid control and improvement of inflammatory symptoms but also exhibit disease-modifying effects (Kirwan, 1995). Dexamethasone (DEX) is one of the most frequently used therapeutic CS. As a synthetic glucocorticoid, it acts primarily through binding to the cytosolic glucocorticoid receptor and causes inhibition of transcriptional factors such as nuclear factor- $\kappa \mathrm{B}$ and activator protein-1, thus suppressing the activation of genes encoding various proinflammatory mediators that aggravate inflammation and cause tissue damage (Coutinho and Chapman, 2011). The rapid actions of DEX are partly ascribed to nongenomic effects by directly regulating signal transduction pathways via membrane-associated glucocorticoid receptors and second messengers (Cato et al., 2002). Despite the significant therapeutic effects of DEX, its sustained use is limited by dose and time-dependent adverse

ABBREVIATIONS: $\mathrm{Cl}$, confidence interval; $\mathrm{CIA}$, collagen-induced arthritis; $\mathrm{CL}$, clearance; Con A, concanavalin A; CPM, counts per minute; CS, corticosteroids; COX, cyclooxygenase; CV\%, coefficient of variation; DEX, dexamethasone; DIS, disease; IL, interleukin; IS, internal standard; ISF, interstitial fluid; LC-MS/MS, liquid chromatography with tandem mass spectrometry; mPBPK, minimal physiologically based pharmacokinetic; NCA, noncompartmental analysis; NPX, naproxen; NSAIDs, nonsteroidal anti-inflammatory drugs; PBS, phosphate-buffered saline; PD, pharmacodynamics; PK, pharmacokinetics; PG, prostaglandins; RA, rheumatoid arthritis; SF, synovial fluid; WBLP, whole blood lymphocyte proliferation. 
effects such as myopathy, growth retardation, metabolic disturbances, and osteoporosis (Saag et al., 1994). Owing to the chronic nature of RA, long-term steroid treatment remains common and necessary for alleviation of active disease activity. As a result, the undesired effects that are commonly associated with long-term and high-dose steroid therapy have a profound influence on the health-related quality of life of RA patients.

NSAIDs are widely prescribed for their potent analgesic, antipyretic, and anti-inflammatory properties. Their pharmacologic effects are mainly attributed to inhibition of cyclooxygenase (COX) and the consequential decreased synthesis of proinflammatory $\mathrm{PG}$, thereby reducing pain and inflammation and improving physical function (Ricciotti and FitzGerald, 2011; Crofford, 2013). Naproxen (NPX), a nonselective COX inhibitor, has been extensively used in the symptomatic management of RA. It shows balanced inhibitory potencies on both COX isoforms, constitutive COX-1 and inflammation-inducible COX-2 (Vane, 1971). NPX is better tolerated with respect to common adverse effects associated with NSAIDs (e.g., gastrointestinal bleeding and potential cardiovascular toxicity) compared with COX-selective NSAIDs (Lussier et al., 1978; Watson et al., 2002). However, like other NSAIDs, NPX is not disease modifying when used alone, thus providing the basis for its frequent use in combination therapy for RA.

Combination therapy has now become standard practice in treatment of RA. In view of the shared pharmacologic effects of DEX and NPX in inhibiting the factors promoting disease production, we hypothesize that their joint use might permit dose reduction of DEX, thereby reducing side effects without compromising efficacy. We assessed the individual and joint pharmacodynamic (PD) effects of DEX and NPX through both in vitro and in vivo studies. Their combined immunosuppressive action was first evaluated via the in vitro inhibition of concanavalin A (Con A)stimulated whole-blood lymphocyte proliferation (WBLP). The pharmacokinetics (PK) of DEX in female and male healthy rats, the PK of NPX after coadministration of DEX, and the effects of NPX and DEX in collagen-induced arthritic (CIA) rats of both sexes were examined. We applied mathematical models incorporating a dual interaction equation to quantitatively describe the joint drug effects and the nature of drug interactions. Further model simulations were conducted to assess the potential degree of steroid dose-sparing effects of NPX.

\section{Materials and Methods}

\section{Reagents and Chemicals}

Pharmaceutic-grade dexamethasone sodium phosphate solution was obtained from Bimeda Pharmaceuticals (Dublin, Ireland). Dexamethasone (purity $>98 \%$ ), sodium naproxen, and Con A were purchased from Sigma-Aldrich (St Louis, MO). Dexamethasone-D5 (internal standard [IS], purity $>98 \%$ ) was purchased from Toronto Research Chemicals (Toronto, ON, Canada).The RPMI 1640 medium (Invitrogen, Grand Island, NY) was used for cell culture and serial dilutions of drugs in the WBLP assay.

\section{Animals}

Male and female Lewis rats (aged 5 to 6 weeks), weighing approximately $110 \mathrm{~g}$ for females and $150 \mathrm{~g}$ for males, were purchased from Harlan (Indianapolis, IN). All rats were housed individually in the University Laboratory Animal Facility under controlled conditions with free access to water and food. Animals were acclimated for 1 week before the experiments. These studies adhered to the Guide for the Care and Use of Laboratory Animals (National Research Council, 2011) and were approved by the University at Buffalo Institutional Animal Care and Use Committee.

\section{WBLP}

The method detailed previously by Ferron and Jusko (1998) was adapted with slight modifications. Briefly, blood (about $4 \mathrm{ml}$ ) from male healthy rats was collected into evacuated heparinized glass tubes and diluted 1:20 (v/v) with RPMI 1640 medium supplemented with $7.5 \%$ fetal calf serum, $100 \mathrm{U} / \mathrm{ml}$ penicillin, $100 \mu \mathrm{g} / \mathrm{ml}$ streptomycin, $2 \mathrm{mM}$ L-glutamine, $20 \mathrm{mM}$ HEPES, and $0.25 \mathrm{mM}$ 2-mercaptoethanol. Then $165 \mu \mathrm{l}$ of the whole blood dilution was plated into each well of a flat bottom, 96-well plate after adding $15 \mu \mathrm{l}$ of mitogen (Con A; stock concentration $133 \mu \mathrm{g} / \mathrm{ml}$ in medium) and $20 \mu \mathrm{l}$ of various concentrations of NPX and DEX alone or combined (Table 1). The cultures were incubated in a $5 \% \mathrm{CO}_{2}$-humidified incubator at $37^{\circ} \mathrm{C}$ for 72 hours, then pulsed with $1 \mu \mathrm{Ci}$ of ${ }^{3} \mathrm{H}$-thymidine per well (New England Nuclear, Boston, MA) and incubated for 18 hours. The cells were harvested onto microplates (Packard Instrument, Meriden, CT), washed with $3 \%$ hydrogen peroxide, dried in an oven at $50^{\circ} \mathrm{C}$ for 2 hours, mildly shaken on a plate shaker for 5 minutes after the addition of liquid scintillation fluid (Microscint-O; Packard Instrument), and counted using a Top Count Microplate Scintillation Counter (Perkin Elmer, Waltham, MA).

\section{PK and PD of DEX and NPX}

The DEX dosing solution was freshly prepared by directly diluting the DEX sodium phosphate solution (equivalent to $3 \mathrm{mg} / \mathrm{ml}$ DEX) with phosphate-buffered saline (PBS). The NPX dosing solution was freshly prepared by dissolving sodium NPX into PBS ( $\mathrm{pH} 8.0$ ), and was filtered through 0.22 micron filters before use. Both drugs were administered in a volume of $1 \mathrm{ml} / \mathrm{kg}$.

The induction of CIA in the Lewis rats was conducted following procedures described elsewhere (Earp et al., 2008b). Hind-paw swelling was used to indicate edema and was measured by digital calipers (VWR Scientific, Rochester, NY). After evaluation on day 15 for females and day 20 for males ( 1 day before peak disease time), the rats with a paw volume increase of at least $50 \%$ in one or two hind paws were selected and used in the subsequent PD study.

For each sex group, the CIA rats were randomly divided into four subgroups $(n=4)$ : vehicle controls, which received only PBS intraperitoneally (i.p.); singledrug groups, which received a bolus injection of either $55 \mathrm{mg} / \mathrm{kg}$ i.p. sodium NPX PBS solution (equivalent to $50 \mathrm{mg} / \mathrm{kg}$ NPX) or $0.225 \mathrm{mg} / \mathrm{kg}$ DEX subcutaneously (s.c.); and the combined group, which received $50 \mathrm{mg} / \mathrm{kg}$ i.p. NPX immediately after s.c. injection of $0.225 \mathrm{mg} / \mathrm{kg}$ DEX. All groups received injections on day 16 for females and day 21 for males after disease induction. Paw edema was measured as the sum of the paw and ankle cross-sectional areas for each hind paw. Paw edema and body weights were monitored before disease induction (day 0 ) and on days $3,7,9,10,11,13,14$, and 15 after induction for both sex groups and days 17 to 20 for CIA males. Starting from the dosing day (day 16 for females and day 21 for males), paw edema was measured before dosing and at 1, 2, 4, 6, 8, 12, 24 , and 36 hours after dosing and on postdose days $3,4,5,6,7,8,9$, and 10. The paw volumes of four female and four male healthy rats were measured through the entire study to determine the natural growth.

The PK of s.c. DEX $(2.25 \mathrm{mg} / \mathrm{kg})$ was studied in female and male healthy rats. Serial blood samples were collected from the saphenous vein at 10,20,30, and 50 minutes after the dose and 1, 1.5, 2, 3, 4, 6, 8, 12, and 24 hours and processed and analyzed for DEX by a liquid chromatography with tandem mass spectrometry (LC-MS/MS) method used previously by others (Samtani and Jusko, 2007) with slight modifications. Briefly, $100 \mu 14 \%$ phosphoric acid was added to $100 \mu \mathrm{l}$ of plasma and then spiked with $10 \mu \mathrm{l}$ of IS working solution. The mixture was vortex-mixed and centrifuged at $13,000 \mathrm{~g}$ for 10 minutes at $10^{\circ} \mathrm{C}$ and then subjected to solid-phase extraction. The dried residue was reconstituted with $200 \mu \mathrm{l}$ of acetonitrile/water $(50: 50, \mathrm{v} / \mathrm{v})$ followed by vortexing and centrifugation at $13,000 \mathrm{~g}$ for 10 minutes at $10^{\circ} \mathrm{C}$. The supernatant was transferred into vials and used for LC-MS/MS injection.

Chromatographic separations were achieved on a C8 Hydrobond AQ Column (particle size $3 \mu \mathrm{m}, 150 \times 2.1 \mathrm{~mm}$; MAC-MOD Analytical, Chadds Ford, PA)

TABLE 1

Concentrations of NPX and DEX tested alone and combined in the WBLP assay

\begin{tabular}{lc}
\hline \multicolumn{1}{c}{ Drug } & Concentrations in WBLP Assay \\
\hline NPX & $0.5,1,5,10,40,100,200,500,1000$, and $2000 \mu \mathrm{M}$ \\
DEX & $0.05,0.1,0.2,0.5,1,2,4,10,20$, and $50 \mathrm{nM}$ \\
Combinations & DEX $(1,2,5$ and $10 \mathrm{nM})+\mathrm{NPX}(50,100,150,200$, \\
and $250 \mu \mathrm{M})$ \\
\hline
\end{tabular}


with the column oven temperature set at $30^{\circ} \mathrm{C}$. The mobile phase consisted of eluent $\mathrm{A}$ (water containing $5 \mathrm{mM}$ ammonium formate and $0.1 \%$ formic acid) and eluent B (acetonitrile/water (95:5 v/v) containing $1 \mathrm{mM}$ ammonium formate and $0.1 \%$ formic acid) and was pumped at a flow rate of $0.2 \mathrm{ml} / \mathrm{min}$ with a gradient elution. The gradient profile was 0 minutes, $40 \% \mathrm{~B}$; a linear increase to $70 \% \mathrm{~B}$ from 0 to 2 minutes; $70 \%$ B for 3 minutes; a linear increase to $95 \%$ B over 0.1 minute; $95 \%$ B for 1.9 minutes; a linear decrease to $40 \%$ B from 7 minutes to 7.1 minutes; $40 \%$ B for 3.9 minutes; and stop at 11.0 minutes. The mass spectrometer was operated in the positive ionization mode for the detection of ion transitions at $m / z$ 393.3/373.3 for DEX and 398.5/378.6 for IS. The system was controlled by Analyst software version 1.4 (Applied Biosystems SciEx, Toronto, ON, Canada) for data acquisition and analysis.

The NPX concentrations in combined-dosing groups were compared with those in the single-drug groups to assess the influence of single-dose DEX on the PK of NPX. Serial blood samples were collected from the saphenous vein at 15 , 30 , and 45 minutes and 1, 2, 4, 6, 9, 12, and 24 hours and analyzed for NPX by LC-MS/MS (Li et al., 2017a).

Linearity was found over the concentration ranges of 0.2 to $100 \mathrm{ng} / \mathrm{ml}$ for DEX and 0.125 to $40 \mu \mathrm{g} / \mathrm{ml}$ for NPX. For both bioanalytic assays, the coefficient of variation (CV\%) of intra- and interday accuracy and precision were less than $15 \%$, and the recovery of the sample preparation method was around $90 \%$ for DEX and approached $100 \%$ for NPX.

\section{PK Models}

The plasma concentration-time profiles of NPX were described by an extended minimal physiologically based pharmacokinetic (mPBPK) model with plasma and one tissue compartment (Fig. 1). Detailed model descriptions and assumptions are provided in (Li et al., 2017b).

The model equations and initial conditions are

$$
\begin{aligned}
& \frac{d A_{a, \mathrm{~N}}}{d t}=-k_{a, \mathrm{~N}} \cdot A_{a, \mathrm{~N}}, \quad A_{a, \mathrm{~N}}(0)=\operatorname{Dose}_{\mathrm{N}} \cdot F_{\mathrm{N}} \\
& \frac{d C_{\mathrm{p}, \mathrm{N}}}{d t}=\left[k_{a, \mathrm{~N}} \cdot A_{a, \mathrm{~N}}+f_{d, N} \cdot Q_{\mathrm{CO}} \cdot\left(C_{u \mathrm{ISF}, \mathrm{N}}-C_{u \mathrm{p}}\right)-\mathrm{CL}_{u \mathrm{p}} \cdot C_{u \mathrm{p}}\right] / V_{\mathrm{p}}, \\
& C_{p, \mathrm{~N}}(0)=0 \\
& \frac{d C_{\mathrm{ISF}}}{d t}=\left[f_{d, \mathrm{~N}} \cdot Q_{\mathrm{CO}} \cdot\left(C_{u \mathrm{p}}-C_{u \mathrm{ISF}, \mathrm{N}}\right)\right] / V_{\mathrm{ISF}}, \quad C_{\mathrm{ISF}}(0)=0
\end{aligned}
$$

where $A_{a, \mathrm{~N}}$ indicates the amount of NPX at the absorption site, $k_{a, \mathrm{~N}}$ is the firstorder absorption rate constant, $C_{p, \mathrm{~N}}$ and $C_{\mathrm{ISF}}$ are total NPX concentrations in $V_{\mathrm{p}}$ (plasma volume) and $V_{\mathrm{ISF}}$ (interstitial fluid volume), $Q_{\mathrm{CO}}$ is cardiac plasma flow, $f_{d, \mathrm{~N}}$ is the fraction of drug in $Q_{\mathrm{CO}}$ accessing $V_{\mathrm{ISF}}, \mathrm{CL}_{\mathrm{up}}$ is clearance of unbound NPX from plasma, $C_{\mathrm{up}}$ and $C_{u \mathrm{ISF}, \mathrm{N}}$ are the unbound NPX concentrations in plasma and ISF that could be calculated from their corresponding total concentrations using the equations, albumin concentrations, and binding parameters provided in $\mathrm{Li}$ et al. (2017a,b), and $F_{\mathrm{N}}$ is the bioavailability of the i.p. dose calculated to be about 0.9 from literature-reported intravenous data in rats (Lauroba et al., 1986)

The physiologic restrictions of relevant parameters are

$f_{d, \mathrm{~N}} \leq 1$ and $V_{\mathrm{p}}+V_{\mathrm{ISF}}=$ Extracellular fluid volume $(\mathrm{ECF}=206.29 \mathrm{ml} / \mathrm{kg})$

(Shah and Betts, 2012). The plasma concentration-time profiles of DEX after $2.25 \mathrm{mg} / \mathrm{kg}$ s.c. injection to female and male healthy rats were characterized by the basic mPBPK model (Cao and Jusko, 2012) shown in Fig. 1. The model equations and initial conditions describing DEX PK are:

$$
\begin{aligned}
& \frac{d A_{a, \mathrm{D}}}{d t}=-k_{a, \mathrm{D}} \cdot A_{a, \mathrm{D}}, \quad \quad A_{a, \mathrm{D}}(0)=\operatorname{Dose}_{\mathrm{D}} \cdot F_{\mathrm{D}} \\
& \frac{d C_{\mathrm{p}, \mathrm{D}}}{d t}=\left[k_{a, \mathrm{D}} \cdot A_{a, \mathrm{D}}+f_{d, \mathrm{D}} \cdot Q_{\mathrm{CO}} \cdot\left(\frac{C_{\mathrm{t}}}{K_{p}}-C_{\mathrm{p}, \mathrm{D}}\right)-\mathrm{CL}_{\mathrm{p}} \cdot C_{\mathrm{p}, \mathrm{D}}\right] / V_{\mathrm{p}}, \\
& C_{\mathrm{p}, \mathrm{D}}(0)=0 \\
& \frac{d C_{t}}{d t}=\left[f_{d, \mathrm{D}} \cdot Q_{\mathrm{CO}} \cdot\left(C_{\mathrm{p}, \mathrm{D}}-\frac{C_{\mathrm{t}}}{K_{p}}\right)\right] / V_{\mathrm{t}}, \quad C_{\mathrm{t}}(0)=0
\end{aligned}
$$

where $A_{a, \mathrm{D}}$ is the amount of DEX at the absorption site, $k_{a, \mathrm{D}}$ is the first-order absorption rate constant, $C_{\mathrm{p}, \mathrm{D}}$ and $C_{\mathrm{t}}$ are total DEX concentrations in $V_{\mathrm{p}}$ and $V_{\mathrm{t}}$ (tissue volume), $K_{p}$ is the tissue partition coefficient, $f_{d, \mathrm{D}}$ is the fraction of drug in $Q_{\mathrm{CO}}$ accessing $V_{\mathrm{t}}, \mathrm{CL}_{\mathrm{p}}$ is the systemic clearance, and $F_{\mathrm{D}}$ is the bioavailabilty of i.m. DEX (0.86) in rats (Samtani and Jusko, 2005; Earp et al., 2008c). The physiologic restrictions of relevant parameters are:

$$
f_{d, \mathrm{D}} \leq 1 \text { and } V_{\mathrm{p}}+V_{\mathrm{t}}=\text { Body weight }
$$

Several modeling assumptions were made for DEX. (1) Unbound DEX concentrations equilibrate rapidly among plasma, ISF, and cell water, so the free

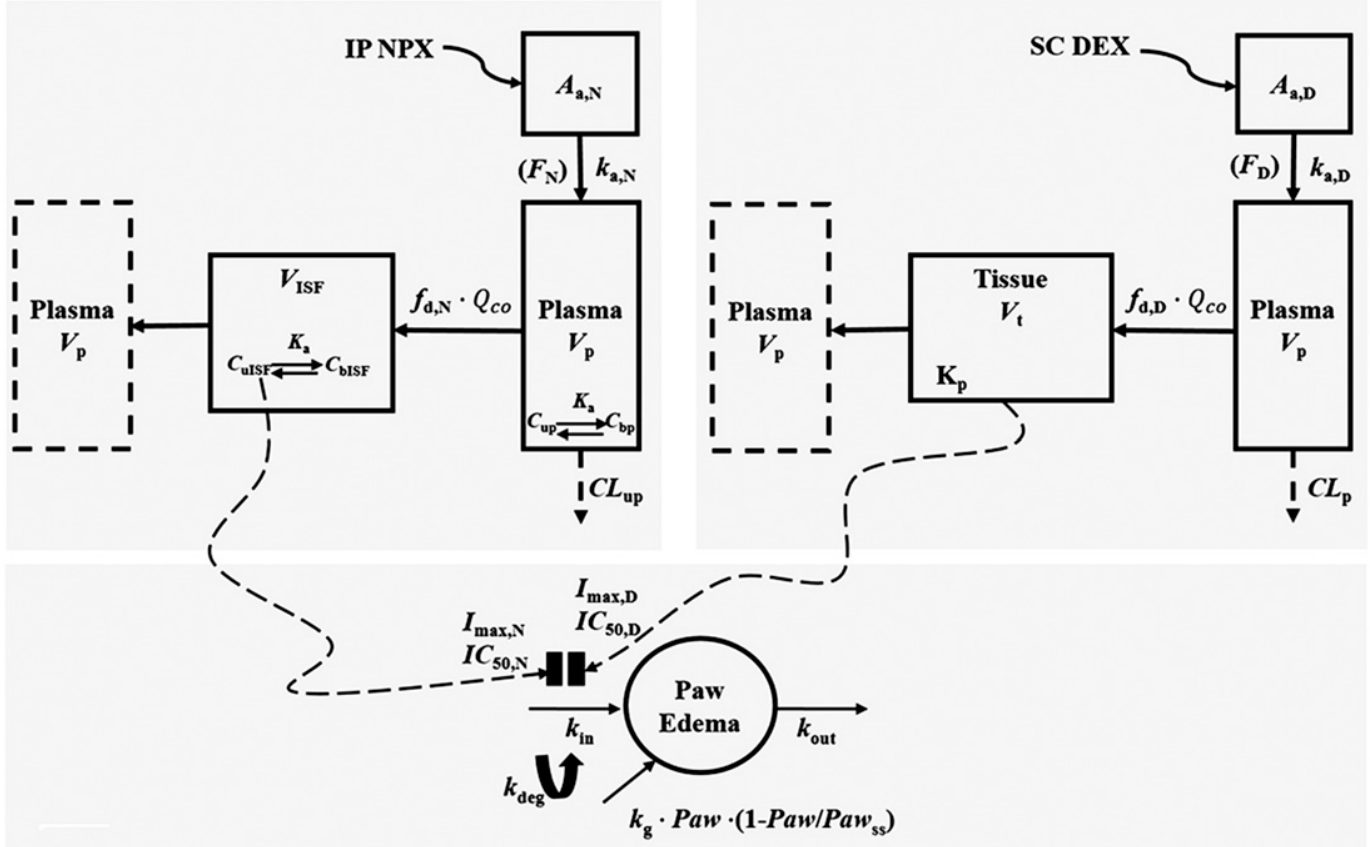

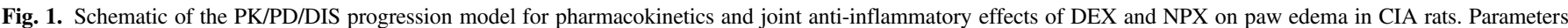
are defined in the text and in Tables 4 and 5. 
ISF DEX concentrations serve as the driving force for PD effects in CIA rats. (2) Protein binding of DEX is linear and occurs primarily to albumin in plasma (Cummings et al., 1990) and tissues with negligible binding to corticosteroidbinding globulin. (3) The binding of DEX to albumin in tissues occurs principally in the ISF. (4) The unbound fraction of DEX in plasma $\left(f_{u \mathrm{p}}\right)$ is 0.3 for both sexes.

The unbound fraction of DEX in ISF $\left(f_{u \text { ISF }}\right)$ was calculated using:

$$
f_{u \mathrm{ISF}}=\frac{1}{1+(E / P)\left(1-f_{u \mathrm{p}}\right) / f_{u \mathrm{p}}}
$$

where $E / P$ is the ratio of protein concentrations in ISF and plasma with a value of 0.9 used for arthritic rats (McNamara et al., 1983, Li et al., 2017a).

The PK of DEX in rats was found to be linear with dose and not affected by RA (Samtani and Jusko, 2005; Earp et al., 2008c); therefore, the PK parameters obtained by fitting the PK data of $2.25 \mathrm{mg} / \mathrm{kg}$ of s.c. DEX in healthy rats were used to simulate the total tissue concentrations of $\operatorname{DEX}\left(C_{\mathrm{t}}\right)$ in arthritic rats that received $0.225 \mathrm{mg} / \mathrm{kg}$ of s.c. DEX. The unbound DEX concentrations in ISF $\left(C_{u \mathrm{ISF}, D}\right)$ were then generated from $C_{u I S F, \mathrm{D}}=C_{\mathrm{t}} \cdot f_{\mathrm{uISF}}$.

\section{PD Models}

Single and Combined Drug Effects on WBLP. The drug effects on Con A-induced lymphocyte proliferation were evaluated by determining the incorporation of ${ }^{3} \mathrm{H}$-thymidine into DNA, which is expressed as counts per minute (CPM). The inhibitory potency on lymphocyte proliferation of individual drug was described using

$$
E=E_{0} \cdot\left(1-\frac{I_{\max } \cdot C^{\gamma}}{\mathrm{IC}_{50}^{\gamma}+C^{\gamma}}\right)
$$

where $E$ is the CPM in the presence of drug, $E_{0}$ is the baseline CPM in the absence of drug, $I_{\max }$ is the maximum effect achieved by either drug, $\mathrm{IC}_{50}$ is the drug concentration at $50 \%$ of maximum inhibition, $C$ is the total concentration of NPX or DEX in the culture medium, and $\gamma$ is the Hill coefficient for the immunosuppressive effect. All model parameters were fitted to the CPM values for each of the four wells of each drug concentration.

The combined inhibitory effects of the two drugs on lymphocyte proliferation were characterized by a joint interaction model (Chakraborty and Jusko, 2002). The published model was modified to allow for the estimation of actual CPM values instead of normalized CPMs. where Paw is the sum of ankle and paw cross-sectional areas of a rat hindfoot; Paw $_{S S}$ is the normal paw size at steady state, $K_{g}$ is the natural first-order growth rate constant of paw in healthy rats, and $t_{\text {onset }}$ is the time delay observed before disease onset.

After disease onset, the paw volume-time profiles in the control group with no drug are

$$
\begin{aligned}
& \frac{d \text { Paw }}{d t}=k_{g} \cdot \text { Paw } \cdot\left(1-\frac{\text { Paw }}{\operatorname{Paw}_{\text {ss }}}\right)+k_{\text {in }}(t)-k_{\text {out }} \cdot \text { Paw }, t \geq t_{\text {onset }} \\
& \operatorname{Paw}(0)=\operatorname{Paw}^{0} \\
& \frac{d k_{\text {in }}}{d t}=-k_{\text {deg }} \cdot k_{\text {in }}, k_{\text {in }}(0)=k_{\text {in }}^{0}
\end{aligned}
$$

where $k_{\text {in }}(t)$ is a function of time and represents the production of paw edema after disease onset; $k_{\mathrm{deg}}$ is a linear decline in $k_{\text {in }}$ accounting for the natural remission of arthritis; and $k_{\text {out }}$ is the first-order rate constant describing the loss of edema.

Based on the mechanisms of drug action, indirect response model I (IDR I) was applied to describe the individual inhibitory effects of NPX and DEX on paw edema production (Dayneka et al., 1993). The rate of change of paw size over time for a single drug were described as

$$
\begin{array}{r}
\frac{d \mathrm{Paw}}{d t}=k_{g} \cdot \operatorname{Paw} \cdot\left(1-\frac{\mathrm{Paw}^{\mathrm{Paw}}}{\mathrm{Paw}_{\mathrm{ss}}}\right)+k_{\mathrm{in}}(t) \cdot\left(1-\frac{I_{\mathrm{max}}^{\prime} \cdot C^{\prime}}{\mathrm{IC}_{50}^{\prime}+C^{\prime}}\right)-k_{\mathrm{out}} \cdot \operatorname{Paw}, t \geq t_{\text {onset }} \\
\operatorname{Paw}(0)=\mathrm{Paw}^{0}
\end{array}
$$

where $I_{\text {max }}^{\prime}$ is the maximum inhibition effect of either NPX or DEX on production of paw edema and $\mathrm{IC}_{50}^{\prime}$ is the unbound ISF concentration $\left(C^{\prime}\right)$ of drug required for $50 \%$ of maximal effect.

The combination effects of NPX and DEX were characterized using a dual drug inhibition approach (Earp et al., 2004). The paw size change over time in combined treatment groups is

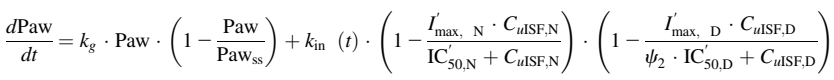

$$
\begin{aligned}
& -k_{\text {out }} \text {. Paw, } t \geq t_{\text {onset }} \\
& \operatorname{Paw}(0)=\operatorname{Paw}^{0}
\end{aligned}
$$

where $\psi_{2}$ is the interaction term for inhibition of paw edema production as defined for eq. 9. The model assumes that the drugs inhibit the proinflammatory processes $\left(k_{\mathrm{in}}\right)$ as directly demonstrated for DEX by Earp et al. (2008b). Values of $I_{\max }$ and $\mathrm{IC}_{50}$ for each drug were generated from their individual studies, allowing $\psi_{2}$ to be resolved from the studies with joint NPX and DEX administration.

$$
E=E_{0} \cdot\left[1-\frac{I_{\mathrm{max}, \mathrm{N}} \cdot\left(\frac{C_{\mathrm{N}}}{\mathrm{IC}_{50, \mathrm{~N}}}\right)^{\gamma_{\mathrm{N}}}+I_{\mathrm{max}, \mathrm{D}} \cdot\left(\frac{C_{\mathrm{D}}}{\left(\psi_{1} \cdot \mathrm{IC}_{50, \mathrm{D}}\right)}\right)^{\gamma_{\mathrm{D}}}+\left(I_{\mathrm{max}, \mathrm{N}}+I_{\mathrm{max}, \mathrm{D}}-I_{\mathrm{max}, \mathrm{N}} \cdot I_{\mathrm{max}, \mathrm{D}}\right) \times\left(\frac{C_{\mathrm{N}}}{I C_{50, \mathrm{~N}}}\right)^{\gamma_{\mathrm{N}}} \cdot\left(\frac{C_{\mathrm{D}}}{\left(\psi_{1} \cdot \mathrm{IC}_{50, \mathrm{D}}\right)}\right)^{\gamma_{\mathrm{D}}}}{\left(\frac{C_{\mathrm{N}}}{\mathrm{I} C_{50, \mathrm{~N}}}\right)^{\gamma_{\mathrm{N}}}+\left(\frac{C_{\mathrm{D}}}{\left(\psi_{1} \cdot \mathrm{IC}_{50, \mathrm{D}}\right)}\right)^{\gamma_{\mathrm{D}}}+\left(\frac{C_{\mathrm{N}}}{\mathrm{IC}_{50, \mathrm{~N}}}\right)^{\gamma_{\mathrm{N}}} \cdot\left(\frac{C_{\mathrm{D}}}{\left(\psi_{1} \cdot \mathrm{IC}_{50, \mathrm{D}}\right)}\right)^{\gamma_{\mathrm{D}}}+1}\right]
$$

where $\psi_{1}$ is the interaction term for lymphocyte proliferation inhibition where values of 1 indicate no interaction, $<1$ synergism, and $>1$ antagonism.

\section{Single and Combined Drug Effects in Rat Arthritis}

Figure 1 depicts a general model scheme for the entire arthritis progression with the anti-inflammatory effects of NPX and DEX acting on paw edema production. The PK/PD model structure for the single drug effects of NPX was presented in Li et al. (2017b). In this model, we assumed that the paw size increase in healthy rats follows logistic growth. Therefore, before disease onset the rate of change of the paw volume over time in all groups is

$$
\frac{d \text { Paw }}{d t}=k_{g} \cdot \text { Paw } \cdot\left(1-\frac{\text { Paw }}{\text { Paw }_{\text {ss }}}\right), t<t_{\text {onset }} \quad \operatorname{Paw}(0)=\text { Paw }^{0}
$$

\section{Model Fitting and Data Analysis}

Naïve-pooled data from all replicates in the WBLP assay were analyzed jointly. Initial noncompartmental analysis (NCA) of the PK data of NPX and DEX was performed using Phoenix WinNonlin 6.4 software (Certara Corporation, Princeton, NJ). All PK data for NPX from our previous study (Li et al., 2017a) and this study were fitted jointly as well as DEX PK data for both sexes. The obtained PK parameter estimates were fixed in the subsequent PD analysis in CIA rats. All model fittings involved nonlinear regression using the maximum likelihood algorithm in ADAPT 5 (Biomedical Simulations Resource, Los Angeles, CA) (D'Argenio et al., 2009). All model codes are provided in the Supplemental Data. The variance model was set as

$$
V_{i}=\left(\sigma_{1}+\sigma_{2} \cdot Y_{i}\right)^{2}
$$


where $V_{i}$ represents the variance of the $i$ th data point, $Y_{i}$ is the $i$ th model prediction, and $\sigma_{1}$ and $\sigma_{2}$ are variance model parameters that were estimated together with other system parameters during model fitting. Model selection was based on the goodness-of-fit criteria which included Akaike Information Criterion (AIC), visual inspection of the fitted profiles, and $\mathrm{CV} \%$ of the parameter estimates. Statistical analysis of PK parameters was performed using SPSS software version 22 (IBM SPSS Statistics, Chicago, IL), and $P<0.05$ was considered statistically significant.

\section{Results}

Single and Combined Effects of DEX and NPX on WBLP. Profiles for single-drug inhibition of lymphocyte proliferation are presented in Fig. 2. Both drugs showed concentration-dependent inhibition of lymphocyte proliferation. The sigmoidal $I_{\max }$ model (eq. 8) was able to capture well the concentration-response relationships of the individual agents. (See the Supplemental Data for model code for single-drug effects in WBLP.) The parameter estimates for single drugs as well as interaction parameters for both drugs and their precision are listed in Table 2.

Both NPX and DEX produced complete suppression of cell proliferation, so both $I_{\max }$ values were fixed to 1.0 . The $\mathrm{IC}_{50}$ of NPX for WBLP was estimated to be $83.97 \mu \mathrm{g} / \mathrm{ml}$, which is slightly lower than reported for human lymphocytes $(350 \mu \mathrm{g} / \mathrm{ml})$ (Panush, 1976). It is very close to the peak plasma concentration $(79 \mu \mathrm{g} / \mathrm{ml})$ achieved in RA patients after $500 \mathrm{mg}$, twice daily doses of NPX (van den Ouweland et al., 1987). This is in accordance with previous findings that the antiproliferative effects of NSAIDs often occur at doses/concentrations high enough to suppress inflammatory responses (Seng and Bayer, 1986). DEX was more efficacious in suppressing lymphocyte proliferation than NPX, as indicated by the 5-fold difference in their log $\mathrm{IC}_{50}$ values. The estimated $\mathrm{IC}_{50}$ value of $\operatorname{DEX}(1.5 \mathrm{ng} / \mathrm{ml})$ is comparable to that using human whole blood culture (3.8 $\mathrm{ng} / \mathrm{ml}$ ) (Mager et al., 2003), which suggests that the antiproliferative effect and sensitivity of the mitogenic response of lymphocytes to DEX are similar across species. The Hill coefficient $\gamma$ was 3.04 for DEX, similar to that for NPX (2.92). The fittings included baseline CPM values for complete assessment of all parameters with potential variability.

The combination effects of NPX and DEX on lymphocyte proliferation were evaluated using 20 concentration combinations. These data were fitted using the joint interaction model (eq. 9) where the interaction term $\psi$ was factored with the $\mathrm{IC}_{50}$ of $\mathrm{DEX}$ because the primary immunosuppressive effects were exerted by DEX. A threedimensional surface plot (Fig. 2C) shows the combined drug effects on lymphocyte proliferation, where the surface represents the model predictions using eq. 9 based on the estimated parameters in Table 2. (See the Supplemental Data for the model code for combined-drug effects in WBLP.) The estimated $\psi_{1}$ value was 0.94 (95\% confidence interval $[\mathrm{CI}], 0.90-0.99)$, which is lower than 1 . Therefore, the
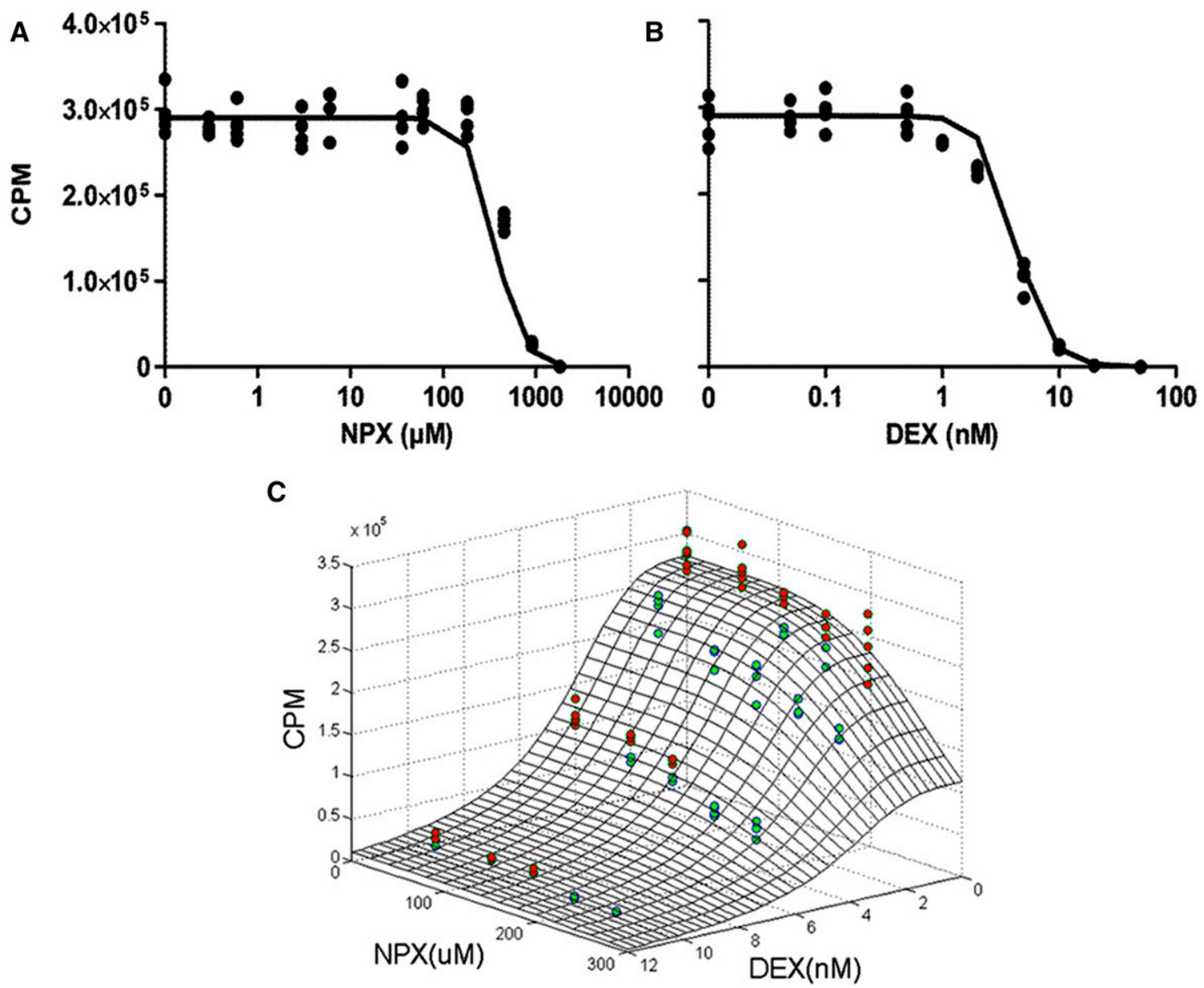

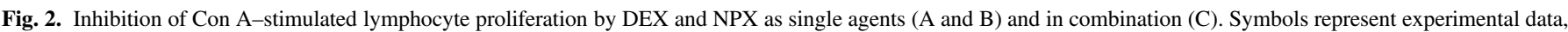

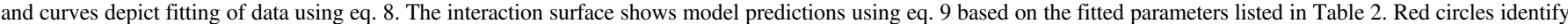
data above the surface, and green circles show data below the surface. 
TABLE 2

Parameter estimates for single and combined effects of NPX and DEX on T lymphocyte proliferation

\begin{tabular}{llcc}
\hline \multirow{2}{*}{ Parameter (Units) } & \multicolumn{1}{c}{ Definition } & Estimates (CV\%) \\
\cline { 2 - 3 } & & NPX & DEX \\
\hline$I_{\max }$ & Maximum inhibition of cell proliferation & 1 (Fixed) & 1 (Fixed) \\
$\mathrm{IC}_{50}(\mu \mathrm{g} / \mathrm{ml})$ & Total drug concentration producing 50\% of maximal effect & $83.97(1.06)$ & $0.0015(1.02)$ \\
$\gamma$ & Hill coefficient & $2.92(4.06)$ & $3.04(1.78)$ \\
$E_{0}$ & Baseline CPM in the absence of drug & $290453(2.12)$ \\
$\psi_{1}$ & Interaction term for inhibition of cell proliferation & $0.94(2.55)$ \\
\hline
\end{tabular}

combination of NPX and DEX exhibits a slight synergistic effect on lymphocyte proliferation.

PK of NPX and DEX in CIA Rats. The PK of NPX in the combined treatment groups was compared with that in the single-drug groups from our previous study ( $\mathrm{Li}$ et al., 2017a). The concentrationtime profiles of NPX in CIA rats after giving $50 \mathrm{mg} / \mathrm{kg}$ NPX alone or together with $0.225 \mathrm{mg} / \mathrm{kg} \mathrm{DEX}$ along with the model fittings and calculated total and unbound ISF NPX concentrations are illustrated in Fig. 3.

The NCA results for the primary PK parameters of NPX including area under the concentration-time curve (AUC), apparent clearance $(\mathrm{CL} / F)$, apparent volume of distribution $(V / F)$, and terminal half-life $\left(t_{1 / 2}\right)$ are listed in Table 3 . No obvious visual differences are seen for the PK profiles, and also no significant differences in the PK parameters were found, suggesting that single-dose DEX did not affect the PK of NPX in CIA rats. Therefore, the PK parameter estimates of NPX obtained using the extended mPBPK model with concentration-dependent protein binding in both plasma and ISF (Fig. 1) from our previous study (Li et al., 2017b) (Table 4) were fixed and applied for the subsequent PD modeling.

The PK of DEX in female and male healthy rats receiving $2.25 \mathrm{mg} / \mathrm{kg}$ of s.c. DEX were assessed (Fig. 4) and described by the basic mPBPK model with one tissue compartment shown in Fig. 1. (See the Supplemental Data for the model code for DEX PK estimation.) The NCA results for the primary PK parameters of DEX indicate that the terminal half-life $\left(t_{1 / 2}\right)$ of DEX is significantly shorter in males (Table 3), so different clearance terms $\left(\mathrm{CL}_{\mathrm{p}}\right)$ were assigned to female and male rats in the model. The mPBPK model was able to capture all the PK data of DEX in healthy rats quite well (Fig. 4) and yielded precise parameter estimates with reasonable $\mathrm{CV} \%$ values (Table 4 ).
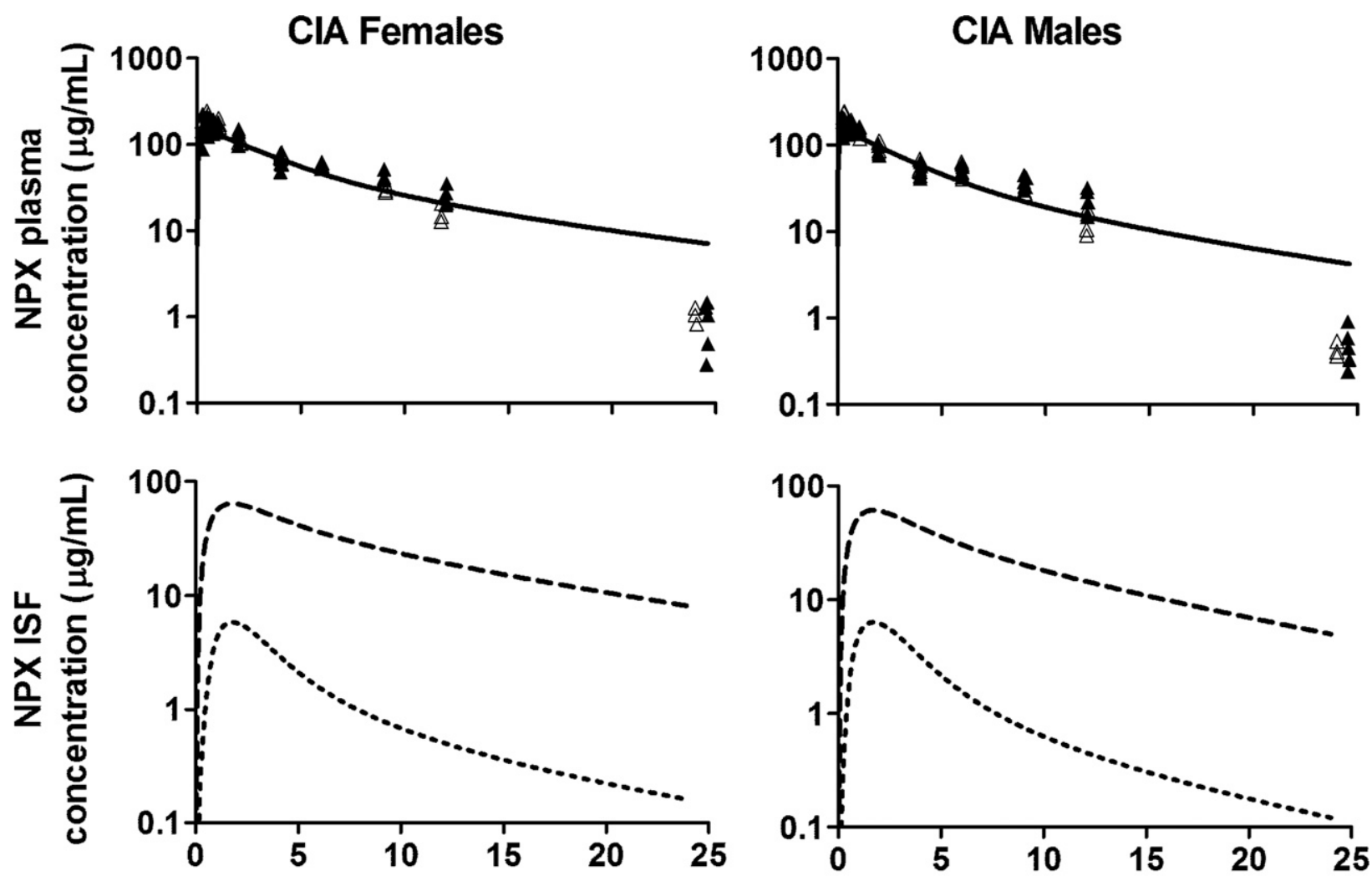

\section{Time (h)}

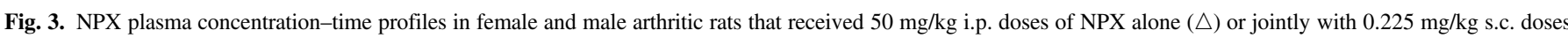

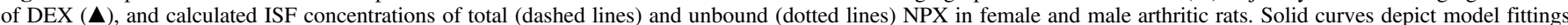
jointly for all dose groups, yielding parameters listed in Table 4. 
TABLE 3

Pharmacokinetic parameters (NCA) based on total plasma concentrations of NPX and DEX after $50 \mathrm{mg} / \mathrm{kg}$ i.p. NPX alone or joint dosing of $0.225 \mathrm{mg} / \mathrm{kg}$ s.c. DEX to arthritic rats and $2.25 \mathrm{mg} / \mathrm{kg}$ s.c. DEX to healthy rats

\begin{tabular}{|c|c|c|c|c|}
\hline Groups & $\begin{array}{c}\text { AUC } \\
\mu g \cdot h / m l\end{array}$ & $\begin{array}{l}\mathrm{CL} / F \\
\mathrm{ml} / \mathrm{h} / \mathrm{kg}\end{array}$ & $\begin{array}{c}V / F \\
\mathrm{ml} / \mathrm{kg}\end{array}$ & $\begin{array}{c}t_{1 / 2} \\
h\end{array}$ \\
\hline \multicolumn{5}{|l|}{ NPX $(50 \mathrm{mg} / \mathrm{kg})$} \\
\hline CIA males (NPX only) & $809.8 \pm 61.0$ & $61.99 \pm 4.87$ & $229.3 \pm 48.9$ & $2.55 \pm 0.36$ \\
\hline CIA males (NPX + DEX) & $876.8 \pm 77.5$ & $57.39 \pm 5.26$ & $198.1 \pm 17.6$ & $2.03 \pm 0.97$ \\
\hline CIA females (NPX only) & $936.0 \pm 42.2$ & $53.43 \pm 2.53$ & $287.1 \pm 42.5$ & $3.74 \pm 0.64$ \\
\hline CIA females (NPX + DEX) & $1021.6 \pm 118.7$ & $49.45 \pm 5.45$ & $192.3 \pm 35.8$ & $2.70 \pm 0.45$ \\
\hline \multicolumn{5}{|l|}{$\mathrm{DEX}(2.25 \mathrm{mg} / \mathrm{kg})$} \\
\hline Healthy males & $10.84 \pm 0.65$ & $208 \pm 12$ & $658 \pm 36$ & $2.19 \pm 0.12$ \\
\hline Healthy females & $12.89 \pm 2.27$ & $179 \pm 35$ & $890 \pm 184$ & $3.45 \pm 0.11^{a}$ \\
\hline
\end{tabular}

AUC, area under the time-concentration curve.

${ }^{a} P<0.05$, statistically significant difference compared with male healthy group.

Plasma volume $\left(V_{\mathrm{p}}\right)$, tissue volume $\left(V_{\mathrm{t}}\right)$, and cardiac plasma flow $\left(Q_{\mathrm{CO}}\right)$ are physiologic parameters applicable to rats obtained from the literature (Shah and Betts, 2012), which were fixed in the model fitting. Absorption of DEX from the s.c. injection site was rapid with a $k_{a}$ value of $2.09 \mathrm{1} / \mathrm{h}$, which is slightly smaller than that obtained after i.m. dosing $(5.781 / \mathrm{h})$ (Earp et al., 2008c). The male rats showed higher clearances $\left(\mathrm{CL}_{\mathrm{p}, \text { Males }}=197.7 \mathrm{ml} / \mathrm{h} / \mathrm{kg}\right)$ than females $\left(\mathrm{CL}_{\mathrm{p}, \text { Females }}=137.8 \mathrm{ml} / \mathrm{h} / \mathrm{kg}\right)$, consistent with the fact that DEX exhibits sex-specific metabolite profiles in rats, where its microsomal metabolism is more rapid in males (Tomlinson et al., 1997).

The estimated tissue partition coefficient $\left(K_{p}\right)$ is 0.63 , for DEX which is close to those calculated from the steady-state distribution volume $\left(V_{\mathrm{ss}} /\right.$ Body weight $\left.=0.7\right)$ and a literature-reported estimation method $(0.5$ for muscle) (Poulin and Theil, 2000). The fraction of cardiac plasma flow of DEX $\left(f_{\mathrm{d}, \mathrm{D}}\right)$ was fixed to 1 , consistent with rapid diffusion of DEX into tissues with blood flow-limited distribution. Model simulations (see the Supplemental Data for the model code for DEX PK simulation) for tissue total and ISF unbound DEX concentrations in arthritic rats receiving $0.225 \mathrm{mg} / \mathrm{kg}$ of s.c. DEX are displayed in Fig. 4, with the latter used as the driving force for PD effects of DEX.

Single and Combined Anti-inflammatory Effects of NPX and DEX. The PK/PD/disease (DIS) progression model displayed in Fig. 1 quantitatively integrated the PK of NPX and DEX into the model for paw edema progression, where unbound ISF concentrations of NPX (Fig. 3) and DEX (Fig. 4) were used to drive their anti-inflammatory effects in arthritic rats. (See the Supplemental Data for the PK/PD/DIS progression model code.) The model was applied to jointly fit the paw volume data from all groups with model fittings illustrated in Fig. 5. The model simultaneously characterized the natural paw growth as well as progression of paw edema with or without treatments very well. All the PD/DIS parameters were estimated quite precisely with reasonable CV $\%$ values (Table 5). The disease-specific parameter estimates for male arthritic rats are comparable to those reported elsewhere (Earp et al., 2009; Lon et al., 2011).

In general, the paw edema RA progression of female and male arthritic rats in our study showed similar patterns and trends with those obtained previously (Li et al., 2017b), where females exhibited higher incidences $(80 \%$ versus $60 \%)$, earlier disease onset $\left(t_{\text {onset }}, 258\right.$ hours versus 307 hours), faster disease production rate (group-averaged $k_{\text {in } 0 \text {, }}$ 2.02 versus $1.78 \mathrm{~mm}^{2} / \mathrm{h}$ ), and more severe symptoms. In the absence of drug, paw size changes over time before disease onset were assumed to follow the logistic growth function (eq. 11) and increased at the same rate as in healthy animals (the estimated $k_{\mathrm{g}}$ was $0.002 \mathrm{~h}^{-1}$ for both sexes).

The individual anti-inflammatory effects of NPX and DEX were characterized using eq. 13. NPX was previously found to be more efficacious in male arthritic rats as demonstrated by the maximum inhibitory effect $\left(I_{\max , \mathrm{N}}^{\prime}, 1.0\right.$ versus 0.75 for females) and concentration for $50 \%$ maximal effect $\left(\mathrm{IC}^{\prime}{ }_{50, \mathrm{~N}}, 136\right.$ versus $221 \mathrm{ng} / \mathrm{ml}$ ) ( $\mathrm{Li}$ et al., 2017b). A pilot study assessing the effects of two single s.c. doses of $\operatorname{DEX}(0.225$ and $2.25 \mathrm{mg} / \mathrm{kg})$ on paw edema in female and male CIA rats was conducted (unpublished), and the paw edema data were described by the mPBPK/PD/DIS progression model (Fig. 1) using unbound ISF DEX concentrations as the driving force for PD. Preliminary fittings revealed values of $I_{\text {max,D }}^{\prime}$ that were 1.0, so it was set as 1.0 for both sexes. A lower $\mathrm{IC}_{50, \mathrm{D}}^{\prime}$ value of $0.39 \mathrm{ng} / \mathrm{ml}$ obtained for males than females

TABLE 4

Pharmacokinetic parameter estimates for DEX (2.25 mg/kg s.c.) and NPX (50 mg/kg i.p.) in rats

\begin{tabular}{llcc}
\hline \multicolumn{1}{c}{ Parameter (Units) } & \multicolumn{1}{c}{ Definition } & Estimates & CV\% \\
\hline$k_{a, \mathrm{D}}(1 / \mathrm{h})$ & Absorption rate constant of DEX & 2.09 & 9.33 \\
$f_{d, \mathrm{D}}$ & Fraction of cardiac plasma flow of DEX & 1 & Fixed \\
$\mathrm{CL}_{\mathrm{p} \text { Females }}(\mathrm{ml} / \mathrm{h} / \mathrm{kg})$ & Clearance of DEX in female rats & 137.8 & 3.51 \\
$\mathrm{CL}_{\mathrm{p} \text { Males }}(\mathrm{ml} / \mathrm{h} / \mathrm{kg})$ & Clearance of DEX in male rats & 197.7 & 3.43 \\
$K_{p}$ & Tissue partition coefficient of DEX & 0.63 & 4.35 \\
$V_{\mathrm{p}}(\mathrm{ml} / \mathrm{kg})$ & Plasma volume & $32.36^{a}$ & Fixed $^{a}$ \\
$V_{\mathrm{t}}(\mathrm{ml} / \mathrm{kg})$ & Tissue volume & $967.6^{a}$ & Fixed \\
$V_{\mathrm{ISF}}(\mathrm{ml} / \mathrm{kg})$ & ISF volume & $173.93^{a}$ & Fixed \\
$Q_{\mathrm{co}}(\mathrm{ml} / \mathrm{h} / \mathrm{kg})$ & Cardiac plasma flow & $7650^{a}$ & Fixed \\
$k_{a, \mathrm{~N}}(1 / \mathrm{h})$ & Absorption rate constant of NPX & $0.98^{b}$ & Fixed \\
$f_{d, \mathrm{~N}}$ & Fraction of cardiac plasma flow of NPX & $0.15^{b}$ & Fixed \\
$\mathrm{CL}_{u \mathrm{p}}(\mathrm{ml} / \mathrm{h} / \mathrm{kg})$ & Unbound clearance of NPX in arthritic rats & $1438^{b}$ & Fixed \\
\hline
\end{tabular}

${ }^{a}$ Physiologic parameter values obtained from Shah and Betts (2012).

${ }^{b} \mathrm{PK}$ parameter values of NPX obtained from Li et al. (2017b). 

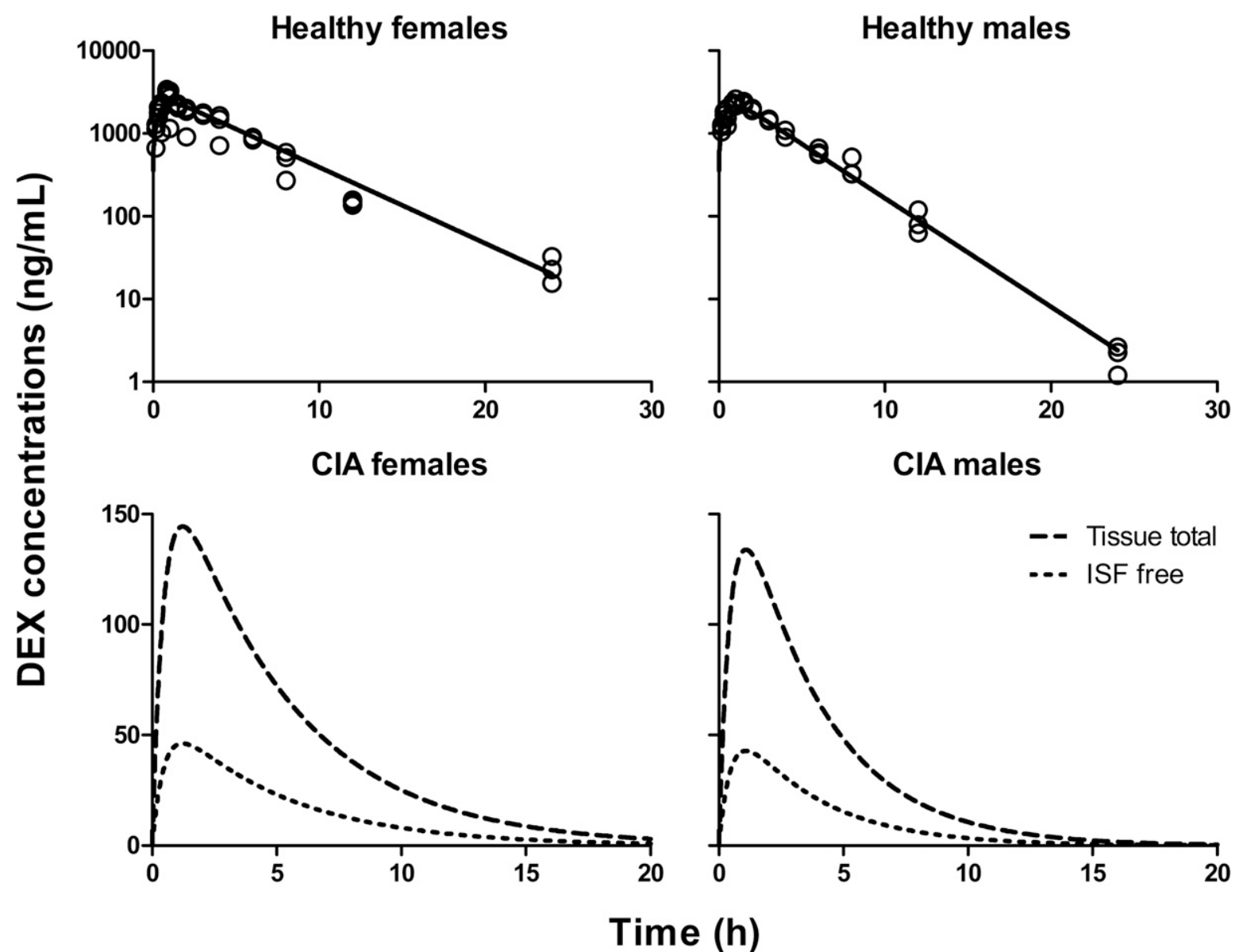

Fig. 4. Total plasma concentration-time profiles of DEX in female and male healthy rats that received $2.25 \mathrm{mg} / \mathrm{kg}$ of s.c. doses of DEX $(O)$, and model-simulated total tissue (dashed lines) and unbound ISF concentrations (dotted lines) of DEX in female and male arthritic rats that received $0.225 \mathrm{mg} / \mathrm{kg}$ of s.c. doses of DEX. Solid curves depict model fittings jointly for all healthy animal groups, yielding parameters listed in Table 4 .

(0.62 ng/ml) (Table 5) suggested that DEX exhibited modestly stronger potency in males, consistent with the effects of NPX.

The strong inhibition of paw edema observed for the combined treatment groups was satisfactorily described by the mPBPK/PD/DIS progression model incorporating the joint interaction equation (eq. 14). During the model fitting, all drug-specific PD parameters $\left(I_{\max }\right.$ and $\left.\mathrm{IC}_{50}\right)$ were fixed to the values listed in Table 5 with only the disease-specific parameters and interaction term $\psi_{2}$ estimated by simultaneously fitting all of the paw volume data from each sex group. The disease-related parameters were re-estimated to account for the between-batch variation of CIA animals. The interaction term $\psi_{2}$ was found to be 1.16 (95\% CI, 0.49-1.84) for females and 0.98 (95\% CI, 0.25-1.71) for males, neither of which was significantly different from 1.0, indicating that the combination of the two drugs displays simple additive effects in both sex groups.

Simulation of Steroid-Sparing Effect of NPX in Arthritis. The $\mathrm{PK} / \mathrm{PD} / \mathrm{DIS}$ progression model well described all the paw volume data when fitted simultaneously with fixed values of certain drug-specific parameters and yielded quite reasonable parameter estimates. Therefore, model simulations were performed based on the fitted parameters (Table 5) to compare the potential anti-inflammatory effects of different single doses of DEX and combinations with NPX on paw edema. This allowed us to evaluate the degree of potential steroid dose-sparing effects of NPX (i.e., Would giving NPX allow a substantially lower dose of DEX to be used to obtain equivalent efficacy to higher doses of DEX?). The same values of initial disease production rate constant $\left(k_{\text {in } 0}\right)$ and paw size on day $0\left(\mathrm{Paw}_{0}\right)$ were assigned to all groups to allow more intuitive comparisons of drug effects. The model-predicted paw edematime profiles after concurrent administration of $50 \mathrm{mg} / \mathrm{kg}$ of NPX and $0.225 \mathrm{mg} / \mathrm{kg}$ of DEX, and various single doses of $\operatorname{DEX}(0.225,2.25$, and $22.5 \mathrm{mg} / \mathrm{kg}$ ) are displayed in Fig. 6. These simulations show that the combination therapy exhibits different degrees of steroid dose-sparing by NPX in female and male arthritic rats. Combined use of DEX $(0.225 \mathrm{mg} / \mathrm{kg})$ with NPX $(50 \mathrm{mg} / \mathrm{kg})$ was able to reduce paw edema to a similar extent as a 10-fold higher dose of DEX $(2.25 \mathrm{mg} / \mathrm{kg})$ for females and a 100 -fold higher dose of DEX $(22.5 \mathrm{mg} / \mathrm{kg})$ for males.

\section{Discussion}

Corticosteroids have long been the mainstay of RA therapy owing to their potent immunosuppressive and anti-inflammatory actions. However, the clinical effectiveness of DEX and other CS is compromised by their long-term and dose-related adverse effects. We extended our previous PK/PD studies with NPX (Li et al., 2017a,b) and DEX (Earp et al., 2008a,b,c) to investigate whether better therapeutic outcomes could be achievable by a combination of DEX and NPX and to ascertain whether sex differences exist.

First, the single and combined immunosuppressive actions of DEX and NPX were evaluated by the in vitro WBLP assay, which measures the mitogenic response of $\mathrm{T}$ lymphocytes to drugs. This assay is convenient to assess the nature and intensity of drug-drug interactions as it mimics the natural milieu and requires small blood volumes. The 
Females

Control \& natural growth

$50 \mathrm{mg} / \mathrm{kg} \mathrm{NPX}$

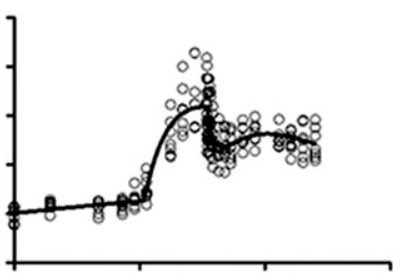

$0.225 \mathrm{mg} / \mathrm{kg}$ DEX

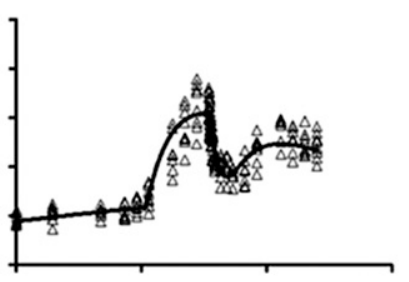

Combination

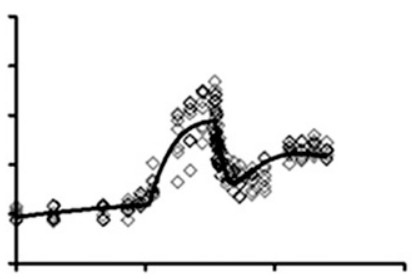

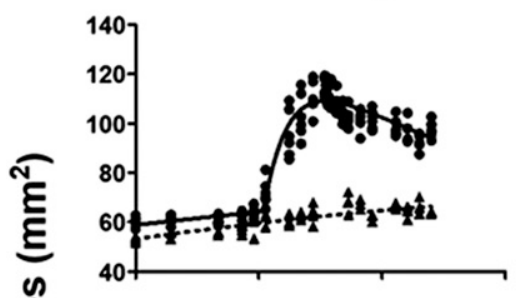
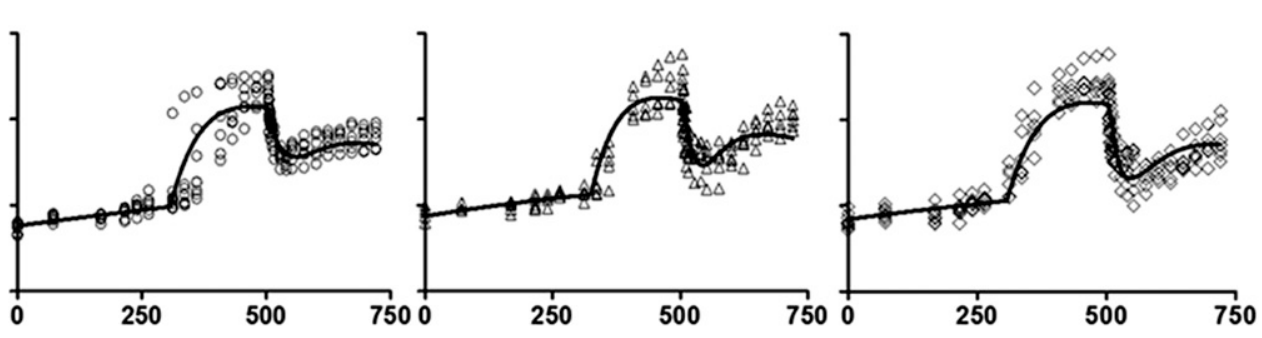

Time post induction (h)

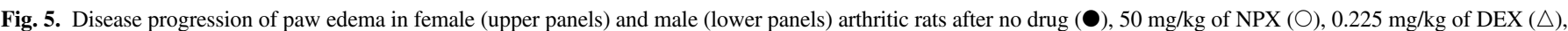

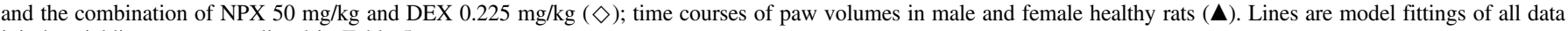
jointly, yielding parameters listed in Table 5.

relative immunosuppressive potency of several therapeutic CS were studied previously using this assay (Mager et al., 2003). DEX inhibits $\mathrm{T}$-lymphocyte proliferation by suppressing nuclear factor- $\kappa \mathrm{B}$, causing reduction of interleukin-2 (IL-2) gene expression, which is responsible for the proliferation and differentiation of T lymphocytes (Toribio et al., 1989).
Insufficient attention has been paid to the immunologic actions of NSAIDs although considerable evidence has shown their capability of suppressing lymphocyte activation (Kelly et al., 1979; Ali et al., 1984; Seng et al., 1990; Cicala et al., 2000). The commonly acknowledged mechanism of action of NSAIDs is to block the synthesis of PG via COX inhibition. However, PG has been reported to inhibit the

TABLE 5

Pharmacodynamic parameter estimates for single and combined effects of DEX and NPX on paw edema in CIA rats

\begin{tabular}{|c|c|c|c|}
\hline \multirow{2}{*}{ Parameters (Units) } & \multirow{2}{*}{ Definition } & \multicolumn{2}{|c|}{ Estimates (CV\%) } \\
\hline & & Females & Males \\
\hline \multicolumn{4}{|c|}{ Disease-specific parameters } \\
\hline$t_{\text {onset }}(\mathrm{h})$ & Time of disease onset & $258(0.44)$ & $307(0.60)$ \\
\hline$k_{\text {out }}(1 / \mathrm{h})$ & Loss of edema rate constant & $0.015(6.07)$ & $0.012(5.37)$ \\
\hline$k_{\mathrm{deg}}(1 / \mathrm{h})$ & Loss of production rate constant & $0.001(5.98)$ & $0.001(8.18)$ \\
\hline$k_{\mathrm{g}}(1 / \mathrm{h})$ & Natural growth rate constant & $0.002(36.0)$ & $0.002(29.5)$ \\
\hline $\operatorname{Paw}_{\mathrm{ss}}\left(\mathrm{mm}^{2}\right)$ & Paw size at steady-state & $72.16(6.64)$ & $103.1(6.60)$ \\
\hline $\mathrm{Paw}_{0, \mathrm{ng}}\left(\mathrm{mm}^{2}\right)$ & Paw size on day 0 for natural growth group & $52.7(2.14)$ & $77.9(1.53)$ \\
\hline$k_{\text {in } 0, \mathrm{c}}\left(\mathrm{mm}^{2} / \mathrm{h}\right)$ & Disease production rate constant at $t_{\text {onset }}$ for control group & $2.18(3.94)$ & $1.72(4.26)$ \\
\hline $\mathrm{Paw}_{0, \mathrm{c}}\left(\mathrm{mm}^{2}\right)$ & Paw size on day 0 for control group & $58.8(1.43)$ & $73.4(1.58)$ \\
\hline$k_{\mathrm{in} 0, D}\left(\mathrm{~mm}^{2} / \mathrm{h}\right)$ & $\begin{array}{l}\text { Disease production rate constant at } t_{\text {onset }} \text { for DEX treatment } \\
\text { group }\end{array}$ & $1.93(4.11)$ & $1.82(4.27)$ \\
\hline $\mathrm{Paw}_{0, \mathrm{D}}\left(\mathrm{mm}^{2}\right)$ & Paw size on day 0 for DEX treatment group & $58.9(1.26)$ & $73.6(1.42)$ \\
\hline$k_{\text {in } 0, \mathrm{~N}}\left(\mathrm{~mm}^{2} / \mathrm{h}\right)$ & $\begin{array}{l}\text { Disease production rate constant at } t_{\text {onset }} \text { for NPX treatment } \\
\text { group }\end{array}$ & $2.06(4.19)$ & $1.79(4.39)$ \\
\hline $\mathrm{Paw}_{0, \mathrm{~N}}\left(\mathrm{~mm}^{2}\right)$ & Paw size on day 0 for NPX treatment group & $60.0(1.29)$ & $70.2(1.55)$ \\
\hline$k_{\text {in } 0, \mathrm{~B}}\left(\mathrm{~mm}^{2} / \mathrm{h}\right)$ & $\begin{array}{l}\text { Disease production rate constant at } t_{\text {onset }} \text { for combined treatment } \\
\text { group }\end{array}$ & $2.00(4.33)$ & $1.80(4.50)$ \\
\hline $\operatorname{Paw}_{0, \mathrm{~B}}\left(\mathrm{~mm}^{2}\right)$ & Paw size on day 0 for combined treatment group & $57.7(1.28)$ & $74.8(1.52)$ \\
\hline \multicolumn{4}{|l|}{ Drug-specific parameters } \\
\hline$I_{\max , \mathrm{N}}^{\prime}$ & Maximum inhibition of NPX on production of paw edema & 0.75 (Fixed) & 1 (Fixed) \\
\hline $\mathrm{IC}_{50, \mathrm{~N}}^{\prime}(\mathrm{ng} / \mathrm{ml})$ & $\begin{array}{l}\text { Unbound ISF concentration of NPX at } 50 \% \text { maximum } \\
\text { inhibition }\end{array}$ & 221 (Fixed) & 136 (Fixed) \\
\hline$I_{\max , \mathrm{D}}^{\prime}$ & Maximum inhibition of DEX on production of paw edema & 1 (Fixed) & 1 (Fixed) \\
\hline $\mathrm{IC}_{50, \mathrm{D}}^{\prime}(\mathrm{ng} / \mathrm{ml})$ & $\begin{array}{l}\text { Unbound ISF concentration of DEX at } 50 \% \text { maximum } \\
\text { inhibition }\end{array}$ & 0.62 (Fixed) & 0.39 (Fixed) \\
\hline \multicolumn{4}{|c|}{ Drug interaction parameter } \\
\hline$\psi_{2}$ & Interaction term for inhibition of paw edema production & $1.16(28.82)$ & $0.98(37.28)$ \\
\hline
\end{tabular}




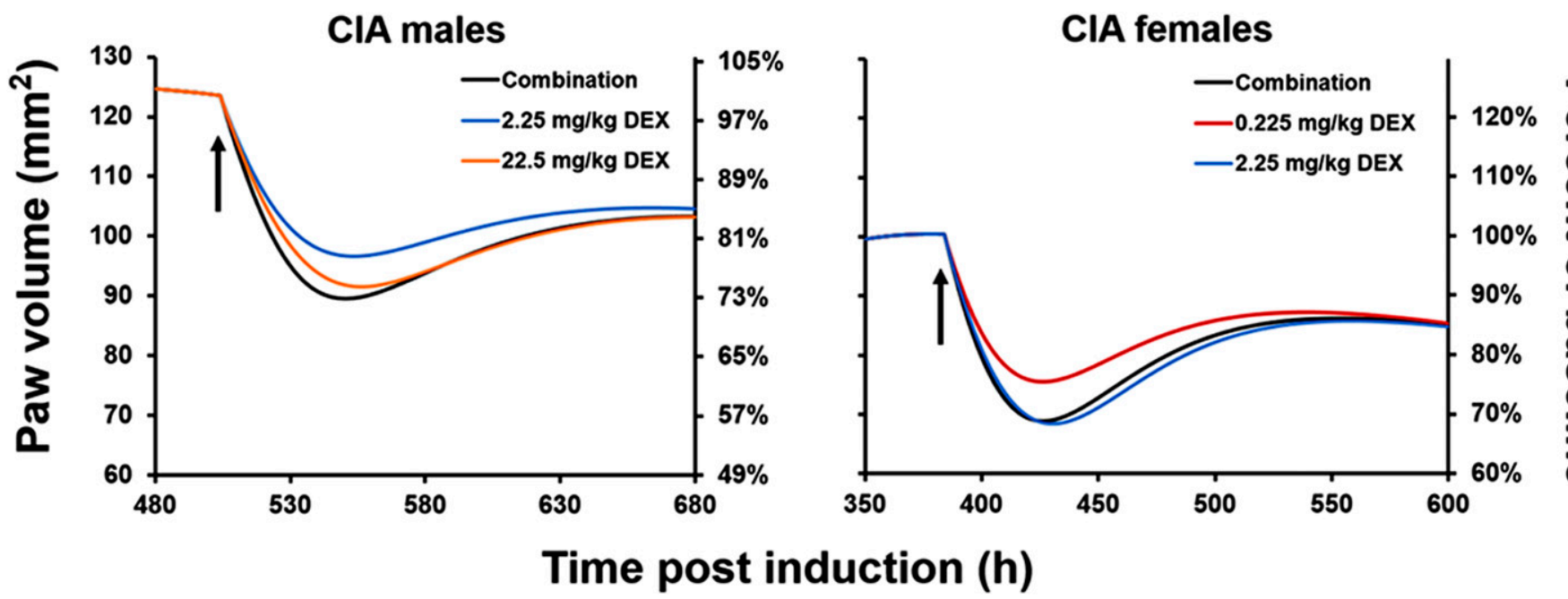

Fig. 6. Model-simulated paw volume versus time profiles after the administration of different single doses of DEX $(0.225,2.25,22.5 \mathrm{mg} / \mathrm{kg})$ and the drug combination (NPX $50 \mathrm{mg} / \mathrm{kg}$ and DEX $0.225 \mathrm{mg} / \mathrm{kg}$ ) in female and male arthritic rats. The secondary $y$-axis indicates the percentage of baseline (paw volume at peak of edema). The black arrows indicate the time of dosing at 380 hours for females and 504 hours for males.

mitogen-induced proliferation of $\mathrm{T}$ cells (Goodwin et al., 1977). Therefore, the antiproliferative effect of NSAIDs may involve COXindependent mechanisms. These drugs have been shown to inhibit DNA synthesis and cause cell growth arrest in the G1 phase (Bayer and Beaven, 1979). The nature and intensity of interactions between DEX and NPX on lymphocyte proliferation were evaluated. The slightly synergistic effect of NPX on the antiproliferative action of $\operatorname{DEX}\left(\psi_{1}<1\right)$ is promising in that combination therapy would add to and possibly potentiate the immunosuppressive activity of DEX.

To further examine the PD interactions between DEX and NPX, the joint anti-inflammatory effects of DEX and NPX were investigated in vivo using CIA rats, a well-established animal model that mirrors human RA (Holmdahl et al., 2001). Similar to humans, the CIA rat model exhibits consistent sex differences in the disease progression of arthritis in that females exhibit higher incidences, earlier disease onset, and worse symptoms. We used this animal model previously to assess the PK/PD of both NPX (Li et al., 2017b) and DEX (Earp et al., 2008a). NPX exhibited moderate but significant inhibitory effects on paw edema production in both sexes with slightly stronger efficacy in male rats, and DEX showed potent anti-inflammatory effects in male arthritic rats, with $60 \%$ reduction of paw edema compared with untreated controls. In particular, DEX-dependent transrepression of production of the cytokines tumor necrosis factor- $\alpha$, IL- $1 \beta$, and IL- 6 plays a central role in the alleviation of paw edema and bone erosion in arthritic rats (Earp et al., 2008a).

Both female and male CIA rats were studied so that the influence of sex in the anti-inflammatory actions of DEX with NPX could be compared. The proposed PK/PD/DIS progression model (Fig. 1) characterized well the anti-inflammatory effects of DEX and NPX both as single agents and in combination. The PK models include an extended mPBPK model with nonlinear binding for NPX adapted from our previous study (Li et al., 2017b) and a basic mPBPK model for DEX. The individual drug effects described by the inhibition model was linked to the calculated unbound ISF concentrations of both NPX and DEX. This was done for several reasons. As shown previously elsewhere ( $\mathrm{Li}$ et al., 2017b), the unbound NPX concentration-time profiles in ISF closely resembled those in synovial fluid, which better correlates with the clinical efficacy of NPX as the synovium is the proposed site of action in RA (Jalava et al., 1977; Netter et al., 1989; Bertin et al., 1994; Day et al., 1995). DEX must permeate cells to bind to receptors and/or alter transcriptional factors, thereby exerting its effects. Rapid equilibration of unbound DEX concentrations between plasma, ISF, and cell water was thus assumed. According to their corresponding mechanisms of action, the joint effect of DEX and NPX was exerted on the production process of paw edema in a joint and noncompetitive manner and was therefore modeled using the dual-drug inhibition approach (Chakraborty and Jusko, 2002; Earp et al., 2004).

The hepatic metabolism of NPX is mainly mediated by cytochrome P450 (CYP) enzymes 1A2 and 2C9 (Miners et al., 1996), which were reported to be induced by DEX in vitro (Gerbal-Chaloin et al., 2002; Vrzal et al., 2009). The NCA results for the primary PK parameters of NPX with or without joint dosing of DEX (Table 3) indicates that the single-dose of DEX had no significant influence on the PK of NPX in either female or male CIA rats.

Previous studies have shown that the PK of DEX in CIA male rats was not altered by RA (Earp et al., 2008c), and DEX concentrations in healthy male rats after s.c. and i.m. dosing have been shown to be identical (Earp et al., 2008a). The same situation was assumed here for female rats, so DEX PK in healthy rats was used to model the PK in arthritic rats. In addition, the PK parameters after i.m. dosing of DEX in female rats were found to be in good agreement with those in males, with $86 \%$ bioavailability for both sexes (Samtani and Jusko, 2005).

We also assumed that the PK of DEX was not altered by NPX. Therefore, the same PK parameter values of DEX were applied for both single and combined drug groups. Male arthritic rats exhibited better responses to NPX, which can be partially explained by the higher unbound ISF concentrations of NPX (Li et al., 2017b). A similar sexspecific response was observed for DEX, consistent with previous findings that the anti-inflammatory actions of CS are more effective in males because they have more glucocorticoid-responsive genes (Duma et al., 2010). The $\mathrm{IC}_{50}$ values of NPX in both sexes are close to the peak unbound NPX concentrations in synovial fluid after a single dose of $500 \mathrm{mg}$ NPX to arthritic patients $(0.13 \mu \mathrm{g} / \mathrm{ml})$ (Day et al., 1995), further confirming the feasibility of using the unbound NPX concentrations in ISF/synovial fluid to mimic the biophase concentrations.

In line with the in vitro results, DEX was more efficacious in reducing paw edema production in both sexes than NPX. For combination treatments in CIA rats, the interaction term $\psi_{2}$ incorporated in the inhibition of paw edema production (eq. 14) is similar to the $\psi_{1}$ in eq. 9, which reflects the magnitude by which the $\mathrm{IC}_{50}$ of $\mathrm{DEX}$ is altered 
by NPX. The estimated $\psi_{2}$ values signified additive effects of combination therapy in both sexes. Nevertheless, model simulations of the anti-inflammatory effects of various dosing regimens demonstrate promising steroid-sparing potential of NPX (Fig. 6), especially for male arthritic rats. The occurrence of additivity is sufficient to produce steroid-sparing effects. The $\psi$ parameter is an empirical term that used to signify the nature of pharmacologic interactions (synergic, additive, or antagonistic) when detailed mechanisms are unclear. Further studies with the measurements of the molecular factors that drive chronic arthritis and that are relevant to the effects of DEX and NPX, such as the cytokines tumor necrosis factor- $\alpha$, IL- $1 \beta$, IL-6, and prostaglandin $\mathrm{E}_{2}$, are necessary to better understand the sexspecific anti-inflammatory actions and the underlying mechanisms of interaction.

Overall, the drug-specific parameters $\left(I_{\max }\right.$ and $\left.\mathrm{IC}_{50}\right)$ of both drugs obtained in vivo were comparable to the in vitro values except that the maximum inhibition of NPX on paw edema in female arthritic rats was less than $1.0\left(I_{\max }=0.75\right)$. This difference is quite reasonable because the whole blood used in the in vitro study was from healthy male rats and, more importantly, the drug effects in vivo incur many additional complicating factors. In our study, the PD models were directly fitted to the actual measured CPM and pooled paw volume data without normalization by the control data, thus avoiding the impact of the variability from control groups (Woo et al., 2009).

In conclusion, the single and joint effects of DEX and NPX on the in vitro mitogen-stimulated proliferation of $\mathrm{T}$ lymphocytes and in assessing paw edema in female and male CIA rats were well described by mathematical models incorporating dual interaction equations for inhibition. With an interaction term $\psi$, the proposed models also indicated the slight extent to which the potency $\left(\mathrm{IC}_{50}\right)$ of $\mathrm{DEX}$ is altered by NPX. Our study has thus mainly demonstrated additive immunosuppressive and anti-inflammatory effects of the drug combination. With the promising steroid-sparing potential of NPX, the combined use of DEX and NPX should permit dose reduction of steroids. The models may be useful to design preclinical studies with related drugs and devise clinical CS dosing regimens that maximize desired effects (immunosuppression and anti-inflammation) while minimizing the unwanted effects in treatment of RA.

\section{Acknowledgments}

The authors thank Donna Ruszaj for technical assistance with LC-MS/MS assay development and the China Scholarship Council for providing the financial support for Xiaonan Li to pursue research at the State University of New York at Buffalo.

\section{Authorship Contributions}

Participated in research design: Li, DuBois, Song, Almon, Jusko, Chen. Conducted experiments: Li, DuBois, Song.

Performed data analysis: Li, Song, Jusko.

Wrote or contributed to writing the manuscript: Li, DuBois, Song, Almon, Jusko, Chen.

\section{References}

Ali AT, Hanson JM, and Morley J (1984) Effects of non-steroidal anti-inflammatory drugs on lymphocyte activation. Agents Actions 14:216-222.

Bayer BM and Beaven MA (1979) Evidence that indomethacin reversibly inhibits cell growth in the G1 phase of the cell cycle. Biochem Pharmacol 28:441-443.

Bertin P, Lapicque F, Payan E, Rigaud M, Bailleul F, Jaeger S, Treves R, and Netter P (1994) Sodium naproxen: concentration and effect on inflammatory response mediators in human rheumatoid synovial fluid. Eur J Clin Pharmacol 46:3-7.

Cao Y and Jusko WJ (2012) Applications of minimal physiologically-based pharmacokinetic models. J Pharmacokinet Pharmacodyn 39:711-723.

Cato AC, Nestl A, and Mink S (2002) Rapid actions of steroid receptors in cellular signaling pathways. Sci STKE 2002-re9.

Cavender D, Haskard D, Yu CL, Iguchi T, Miossec P, Oppenheimer-Marks N, and Ziff M (1987)

Pathways to chronic inflammation in rheumatoid synovitis. Fed Proc 46:113-117.
Chakraborty A and Jusko WJ (2002) Pharmacodynamic interaction of recombinant human interleukin-10 and prednisolone using in vitro whole blood lymphocyte proliferation. J Pharm Sci 91:1334-1342.

Cicala C, Ianaro A, Fiorucci S, Calignano A, Bucci M, Gerli R, Santucci L, Wallace JL, and Cirino $\mathrm{G}$ (2000) NO-naproxen modulates inflammation, nociception and downregulates T cell response in rat Freund's adjuvant arthritis. Br J Pharmacol 130:1399-1405.

Coutinho AE and Chapman KE (2011) The anti-inflammatory and immunosuppressive effects of glucocorticoids, recent developments and mechanistic insights. Mol Cell Endocrinol 335:2-13. Coxib and Traditional NSAID Trialists' (CNT) Collaboration, Bhala N, Emberson J, Merhi A, Abramson S, Arber N, Baron JA, Bombardier C, Cannon C, Farkouh ME, FitzGerald GA, et al. (2013) Vascular and upper gastrointestinal effects of non-steroidal anti-inflammatory drugs: meta-analyses of individual participant data from randomised trials. Lancet 382:769-779.

Crofford LJ (2013) Use of NSAIDs in treating patients with arthritis. Arthritis Res Ther 15 (Suppl 3):S2.

Cummings DM, Larijani GE, Conner DP, Ferguson RK, and Rocci, JrML (1990) Characterization of dexamethasone binding in normal and uremic human serum. DICP 24:229-231.

Day RO, Francis H, Vial J, Geisslinger G, and Williams KM (1995) Naproxen concentrations in plasma and synovial fluid and effects on prostanoid concentrations. J Rheumatol 22:2295-2303.

D'Argenio D, Schumitzky A, and Wang X (2009) Adapt 5 User's Guide: Pharmacokinetic Pharmacodynamic Systems Analysis Software, BMSR. University of Southern California, Los Angeles.

Duma D, Collins JB, Chou JW, and Cidlowski JA (2010) Sexually dimorphic actions of glucocorticoids provide a link to inflammatory diseases with gender differences in prevalence. $S C$ Signal 3:ra74.

Dayneka NL, Garg V, and Jusko WJ (1993) Comparison of four basic models of indirect pharmacodynamic responses. J Pharmacokinet Biopharm 21:457-478.

Earp J, Krzyzanski W, Chakraborty A, Zamacona MK, and Jusko WJ (2004) Assessment of drug interactions relevant to pharmacodynamic indirect response models. J Pharmacokinet Pharmacodyn 31:345-380.

Earp JC, Dubois DC, Almon RR, and Jusko WJ (2009) Quantitative dynamic models of arthritis progression in the rat. Pharm Res 26:196-203.

Earp JC, Dubois DC, Molano DS, Pyszczynski NA, Almon RR, and Jusko WJ (2008a) Modeling corticosteroid effects in a rat model of rheumatoid arthritis II: mechanistic pharmacodynamic model for dexamethasone effects in Lewis rats with collagen-induced arthritis. J Pharmacol Exp Ther 326:546-554.

Earp JC, Dubois DC, Molano DS, Pyszczynski NA, Keller CE, Almon RR, and Jusko WJ (2008b) Modeling corticosteroid effects in a rat model of rheumatoid arthritis I: mechanistic disease progression model for the time course of collagen-induced arthritis in Lewis rats. J Pharmacol Exp Ther 326:532-545.

Earp JC, Pyszczynski NA, Molano DS, and Jusko WJ (2008c) Pharmacokinetics of dexamethasone in a rat model of rheumatoid arthritis. Biopharm Drug Dispos 29:366-372.

Ferron GM and Jusko WJ (1998) Species- and gender-related differences in cyclosporine/ prednisolone/sirolimus interactions in whole blood lymphocyte proliferation assays. J Pharmacol Exp Ther 286:191-200.

Gaffo A, Saag KG, and Curtis JR (2006) Treatment of rheumatoid arthritis. Am J Health Syst Pharm 63:2451-2465.

Gerbal-Chaloin S, Daujat M, Pascussi JM, Pichard-Garcia L, Vilarem MJ, and Maurel P (2002) Transcriptional regulation of CYP2C9 gene. Role of glucocorticoid receptor and constitutive androstane receptor. J Biol Chem 277:209-217.

Goodwin JS, Bankhurst AD, and Messner RP (1977) Suppression of human T-cell mitogenesis by prostaglandin. Existence of a prostaglandin-producing suppressor cell. J Exp Med 146: 1719-1734.

Holmdahl R, Lorentzen JC, Lu S, Olofsson P, Wester L, Holmberg J, and Pettersson U (2001) Arthritis induced in rats with nonimmunogenic adjuvants as models for rheumatoid arthritis. Immunol Rev 184:184-202.

Jalava S, Saarimaa H, Anttila M, and Sundquist H (1977) Naproxen concentrations in serum, synovial fluid, and synovium. Scand J Rheumatol 6:155-157.

Jawaheer D, Lum RF, Gregersen PK, and Criswell LA (2006) Influence of male sex on disease phenotype in familial rheumatoid arthritis. Arthritis Rheum 54:3087-3094.

Kelly JP, Johnson MC, and Parker CW (1979) Effect of inhibitors of arachidonic acid metabolism on mitogenesis in human lymphocytes: possible role of thromboxanes and products of the lipoxygenase pathway. J Immunol 122:1563-1571.

Kirwan JR; The Arthritis and Rheumatism Council Low-Dose Glucocorticoid Study Group (1995) The effect of glucocorticoids on joint destruction in rheumatoid arthritis. $N$ Engl J Med 333: $142-146$.

Lauroba J, Doménech J, Moreno J, and Plá-Delfina JM (1986) Relationships between biophasic disposition and pharmacokinetic behavior in nonsteroid antiinflammatory drugs. Arzneimittelforschung 36:710-714

Li X, DuBois DC, Almon RR, and Jusko WJ (2017a) Effect of disease-related changes in plasma albumin on the pharmacokinetics of naproxen in male and female arthritic rats. Drug Metab Dispos 45:476-483

Li X, DuBois DC, Almon RR, and Jusko WJ (2017b) Modeling sex differences in pharmacokinetics, pharmacodynamics, and disease progression effects of naproxen in rats with collageninduced arthritis. Drug Metab Dispos 45:484-491.

Lon HK, Liu D, Zhang Q, DuBois DC, Almon RR, and Jusko WJ (2011) Pharmacokineticpharmacodynamic disease progression model for effect of etanercept in Lewis rats with collageninduced arthritis. Pharm Res 28:1622-1630.

Lussier A, Arsenault A, and Varady J (1978) Gastrointestinal microbleeding after aspirin and naproxen. Clin Pharmacol Ther 23:402-407.

Mager DE, Moledina N, and Jusko WJ (2003) Relative immunosuppressive potency of therapeutic corticosteroids measured by whole blood lymphocyte proliferation. J Pharm Sci 92:1521-1525.

McInnes IB and Schett G (2011) The pathogenesis of rheumatoid arthritis. N Engl J Med 365: 2205-2219.

McNamara PJ, Gibaldi M, and Stoeckel K (1983) Fraction unbound in interstitial fluid. J Pharm Sci 72:834-836.

Miners JO, Coulter S, Tukey RH, Veronese ME, and Birkett DJ (1996) Cytochromes P450, 1A2, and 2C9 are responsible for the human hepatic O-demethylation of R- and S-naproxen. Biochem Pharmacol 51:1003-1008.

National Research Council (NRC) (2011) Guide for the Use and Care of Laboratory Animals 8th ed. National Academies Press, Washington, DC 
Netter P, Bannwarth B, and Royer-Morrot MJ (1989) Recent findings on the pharmacokinetics of non-steroidal anti-inflammatory drugs in synovial fluid. Clin Pharmacokinet 17:145-162.

Panush RS (1976) Effects of certain antirheumatic drugs on normal human peripheral blood lymphocytes. Inhibition of mitogen- and antigen-stimulated incorporation of tritiated thymidine Arthritis Rheum 19:907-917.

Poulin P and Theil FP (2000) A priori prediction of tissue:plasma partition coefficients of drugs to facilitate the use of physiologically-based pharmacokinetic models in drug discovery. $J$ Pharm Sci 89:16-35.

Ricciotti E and FitzGerald GA (2011) Prostaglandins and inflammation. Arterioscler Thromb Vasc Biol 31:986-1000.

Saag KG, Koehnke R, Caldwell JR, Brasington R, Burmeister LF, Zimmerman B, Kohler JA, and Furst DE (1994) Low dose long-term corticosteroid therapy in rheumatoid arthritis: an analysis of serious adverse events. Am J Med 96:115-123.

Samtani MN and Jusko WJ (2005) Comparison of dexamethasone pharmacokinetics in female rats after intravenous and intramuscular administration. Biopharm Drug Dispos 26:85-91.

Samtani MN and Jusko WJ (2007) Quantification of dexamethasone and corticosterone in rat biofluids and fetal tissue using highly sensitive analytical methods: assay validation and application to a pharmacokinetic study. Biomed Chromatogr 21:585-597.

Seng GF and Bayer BM (1986) Inhibition of amino acid transport by nonsteroidal anti-inflammatory drugs: a model for predicting relative therapeutic potency. J Pharmacol Exp Ther 237:496-503.

Seng GF, Benensohn J, and Bayer BM (1990) Changes in T and B lymphocyte proliferative responses in adjuvant-arthritic rats: antagonism by indomethacin. Eur $J$ Pharmacol 178 267-273.

Shah DK and Betts AM (2012) Towards a platform PBPK model to characterize the plasma and tissue disposition of monoclonal antibodies in preclinical species and human. $J$ Pharmacokinet Pharmacodyn 39:67-86.

Smolen JS, Aletaha D, and McInnes IB (2016) Rheumatoid arthritis. Lancet 388:2023-2038

Tomlinson ES, Maggs JL, Park BK, and Back DJ (1997) Dexamethasone metabolism in vitro: species differences. J Steroid Biochem Mol Biol 62:345-352.
Toribio ML, Gutiérrez-Ramos JC, Pezzi L, Marcos MA, and Martínez C (1989) Interleukin-2dependent autocrine proliferation in T-cell development. Nature 342:82-85.

van den Ouweland FA, Franssen MJ, van de Putte LB, Tan Y, van Ginneken CA, and Gribnau FW (1987) Naproxen pharmacokinetics in patients with rheumatoid arthritis during active polyarticular inflammation. Br J Clin Pharmacol 23:189-193.

van Vollenhoven RF (2009) Sex differences in rheumatoid arthritis: more than meets the eye.... BMC Med 7:12.

Vane JR (1971) Inhibition of prostaglandin synthesis as a mechanism of action for aspirin-like drugs. Nat New Biol 231:232-235.

Vrzal R, Stejskalova L, Monostory K, Maurel P, Bachleda P, Pavek P, and Dvorak Z (2009) Dexamethasone controls aryl hydrocarbon receptor (AhR)-mediated CYP1A1 and CYP1A2 expression and activity in primary cultures of human hepatocytes. Chem Biol Interact 179: 288-296.

Watson DJ, Rhodes T, Cai B, and Guess HA (2002) Lower risk of thromboembolic cardiovascular events with naproxen among patients with rheumatoid arthritis. Arch Intern Med 162: $1105-1110$.

Woo S, Pawaskar D, and Jusko WJ (2009) Methods of utilizing baseline values for indirect response models. J Pharmacokinet Pharmacodyn 36:381-405.

Address correspondence to: Dr. William J. Jusko, Department of Pharmaceutical Sciences, School of Pharmacy and Pharmaceutical Sciences, State University of New York at Buffalo, Buffalo, NY. E-mail: wjjusko@buffalo.edu or Dr. Xijing Chen, Clinical Pharmacokinetics Laboratory, School of Basic Medicine and Clinical Pharmacy. China Pharmaceutical University, Nanjing, Jiangsu, 211198, People's Republic of China. E-mail: chenxj-lab@hotmail.com 